\title{
Flexural Strengthening of Damaged T-Joists with Severe Corrosion Using CFRP Sheets
}

\author{
Jose Vercher, ${ }^{1}$ Enrique Gil, ${ }^{2}$ Ángeles Mas, ${ }^{1}$ Carlos Lerma, ${ }^{1}$ and M. Eugenia Torner ${ }^{2}$ \\ ${ }^{1}$ Department of Architectural Constructions, Universitat Politècnica de València, Camino de Vera, s/n, 46022 Valencia, Spain \\ ${ }^{2}$ Department of Structural Construction, Universitat Politècnica de València, Camino de Vera, s/n, 46022 Valencia, Spain \\ Correspondence should be addressed to Jose Vercher; jvercher@csa.upv.es
}

Received 27 January 2017; Accepted 19 February 2017; Published 12 March 2017

Academic Editor: Francesco Caputo

Copyright (c) 2017 Jose Vercher et al. This is an open access article distributed under the Creative Commons Attribution License, which permits unrestricted use, distribution, and reproduction in any medium, provided the original work is properly cited.

\begin{abstract}
This paper evaluates the residual safety of isolated T-joists with severe corrosion for the two extreme cases of boundary conditions, simply supported and fixed-ended, in order to help in making decisions about the magnitude of the necessary intervention. When the T-joist is part of a complete slab, the boundary conditions will be in an intermediate situation between these two extreme cases, so that it is possible to assess the safety with respect to its degree of embedding. The research is conducted for the cases of healthy T-joist, T-joist with complete corrosion of the lower reinforcement, and repaired T-joists with a variable number of CFRP sheets. This work is based on the ACI 318 load test to maintain a structure in use and proposes a Load Factor (LF), which estimates the safety reserve. The simply supported T-joists specimens with severe corrosion do not meet the Load Factor or ACI 318 criteria, even with a large number of CFRP sheets. On the other hand, fixed-ended cases can be kept in use despite corrosion by applying light CFRP strengthening, and with four sheets the initial safety is restored.
\end{abstract}

\section{Introduction}

The rehabilitation sector has achieved a greater importance than the construction of new buildings in recent years, due to the crisis in the construction of buildings. According to the Instituto de Tecnología de la Construcción [1], the forecasts for the coming years in Spain indicate that rehabilitation will be the sector with more activity (Figure 1). Because of this, it is essential to pay attention to the entire set of actions carried out in cases of rehabilitation.

But in the growing sector of rehabilitation, the flexural elements are the structural elements in which the higher percentages of damage appear. In Spain, lesions appear in $25.6 \%$ of the slabs, and corrosion in one-way slabs represents $68 \%$ of these cases [2].

In some cases of large damage, the severe corrosion of the lower level of tendons of a joist causes the spalling of the lower concrete cover. This effect is enhanced by the use of aluminous cement in prefabrication, widely used for a few decades because of its shorter time of manufacture. This occurs due to the conversion of this type of cement, since the concrete becomes more porous and attackable and less resistant [3]. In Spain, it is estimated that, of the 3,400,000 households built between 1950 and 1970, between 12 and 24\% of them have used this type of cement in the slabs [4].

When the technicians analyze a case of structural pathology, they find the difficulty of assessing the remaining safety, in order to decide the magnitude of the intervention to be performed. This research quantifies the residual safety and helps to make this important decision.

Strengthening may be required when structures are damaged due to an aggressive environment. In these cases, the most common rehabilitation techniques have been accomplished by the use of conventional materials such as steel structural profiles (see Figure 2). However, recently the use of innovative materials like fiber-reinforced polymer (FRP) has emerged as an alternative to the use of the conventional techniques and it seems to be the most promising method to be used in structural engineering [5].

FRP is typically organized in a laminated structure, where each sheet contains an arrangement of unidirectional fibers or woven fiber fabrics embedded within a thin layer of 


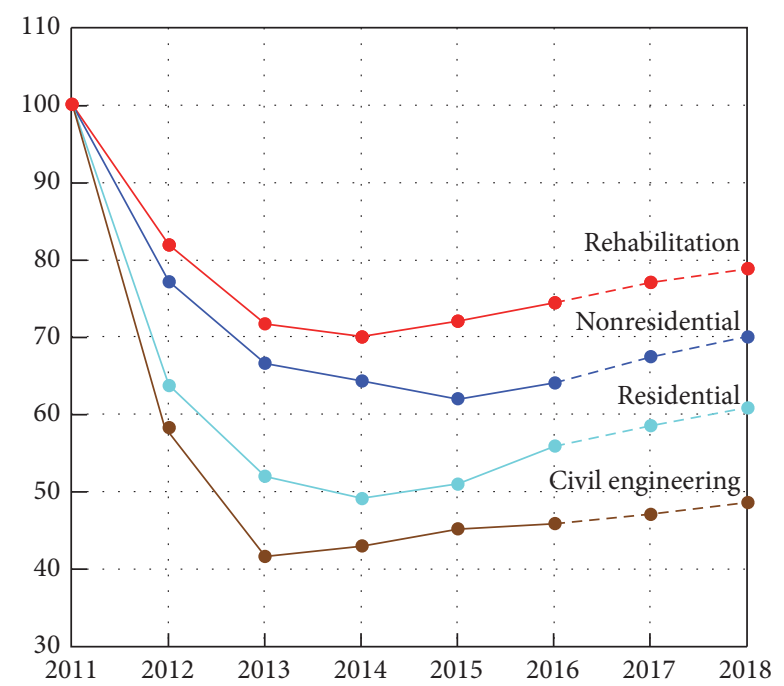

FIgURE 1: Evolution of the different subsectors in the Spanish building construction market. Production rates at constant prices, basis $2011=100$.

(a)

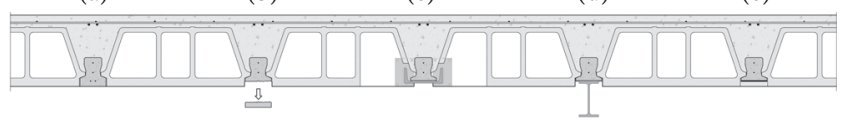

Figure 2: Constructive detail (a) healthy joist, (b) joist with severe corrosion and spalling, (c) joist repaired with UPN profile, (d) joist repaired with IPE profile, and (e) joist repaired with CFRP sheet.

light polymer matrix material. Fibers are typically composed of carbon, aramid, or glass. The matrix protects the fibers from damage and transfers the stresses between fibers. This matrix is commonly made of polyester, epoxy, or nylon. There are two additional types of FRP composite, bidirectional fibers, which are used commonly for strengthening two-way slabs, and the FRP rods, which became an alternative for reinforcement steel bars [6].

Externally bonded FRP reinforcement has been shown to be applicable for the strengthening of many types of reinforced concrete (RC) structures such as columns, beams, slabs, and walls and can be used to improve flexural and shear capacities [7-9] and also provide confinement and ductility to compression members [10-12].

Externally bonded strengthening system, where the FRP sheets or plates are bonded to the concrete tensile surface, is widely used to improve the flexural capacity of concrete structures. Their application has multiple benefits, including increased ultimate flexural strength capacity and increased postcracking stiffness, as well as concrete crack control [13], high tensile strength, high durability, minimum increases in structural size and weight, ease of site handling, and good corrosion resistance. There are even some studies that aim to improve the properties of FRP sheets with carbon nanotubes or graphene nanoplatelets $[14,15]$. Recently, near-surfacemounted technique was introduced, where the FRP bars of plates are inserted into a groove made in the concrete surface [16].

Although there are some authors who evaluate other types of FRP [17], the Carbon Fiber-Reinforced Polymer (CFRP) is mostly employed. There are numerous works which research about externally bonded CFRP reinforcement in order to strengthen many types of RC structures to resist higher design loads [18-22], but there is less available research on corroded, patched, and CFRP-repaired RC specimens [23, 24].

Most of the work done by other authors is centered on isolated linear elements, usually beams, although there is some study of bidirectional elements like solid slabs [25]. There is no research on safety of joists inside a one-way slab. The aim of this research is to evaluate the residual safety increase of joists with a high degree of damage when they are part of a complete unidirectional slab, by gluing CFRP sheets on the underside. For this reason, specimens of isolated T-joists are assessed, with the different boundary conditions of usual modeling in structure analysis (simply supported and fixed-ended). When the joist is in a slab, its boundary conditions will be between these two extreme cases, so that we can assess its safety with respect to the degree of embedding that they have. This work focuses on the evaluation of slabs whose failure is dominated by flexion. This happens in most cases, because corrosion usually occurs in the lower reinforcement, due to it has less concrete cover.

\section{Materials and Methods}

Researchers have not made great efforts to accurately assess the remaining safety in cases of corrosion, in the field of building construction. The habitual action is to repair or reinforce, leaving the existing building on the side of safety.

The structural simplification of considering the actual three-dimensional elements such as lines does not represent the minimum balance of work with which they behave in reality. The loads are transmitted in various simultaneous forms in space. Mechanisms such as struts and ties or the arch effect appear in the elements subjected to flexion and contribute considerably if these elements have the horizontal displacement restrained. Because of this, it is necessary to study the elements in three dimensions, to properly assess the safety they possess.

2.1. Methodology for Assessing the Remaining Safety. The methodology used for the evaluation of the remaining safety of prestressed joists with severe corrosion and repaired with CFRP sheets is similar to the one the authors have developed in some publications of pathology in complete buildings [26], but in this case with CFRP strengthening. The novelty of this research is that it quantifies the remaining safety. Some healthy and damaged specimens of prestressed joist with compression layer (T-section) are simulated with ANSYS finite element software. With these simulations, the loadvertical displacement curves at midspan can be drawn. The proposed method to assess the remaining safety is based on the study of two aspects in these behavioral curves. First, the ACI 318 [27] load test for existing structures indicates 

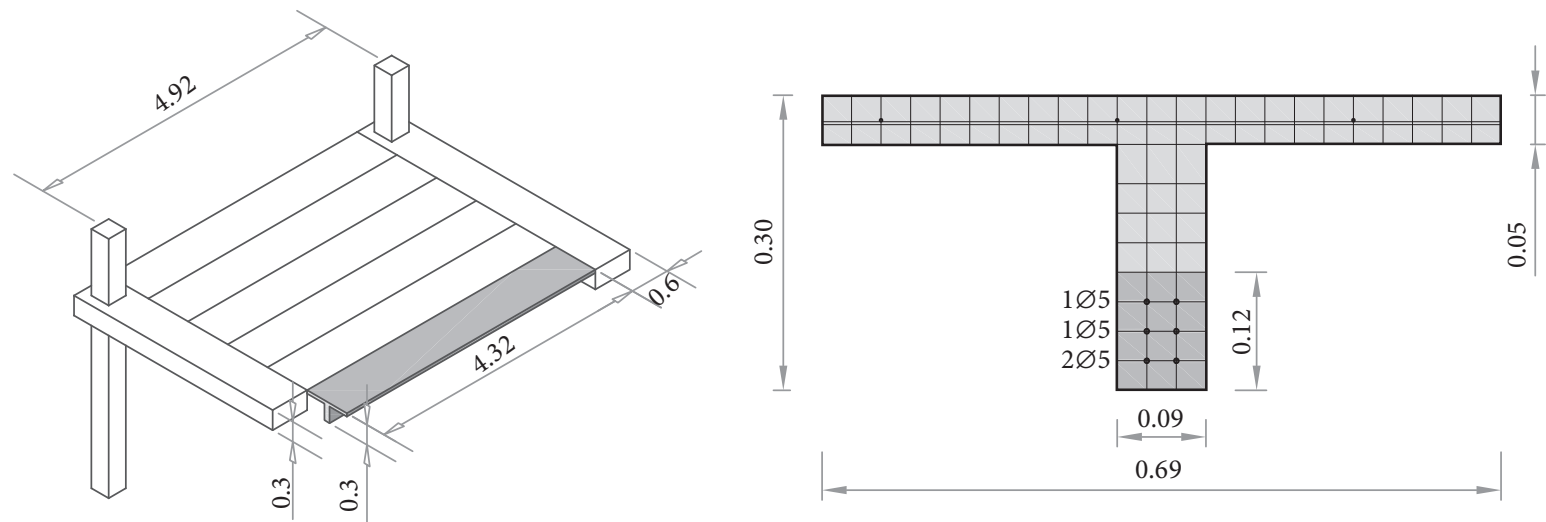

Figure 3: Simulated T-joist.

TABLE 1: Process of load application.

\begin{tabular}{lc}
\hline Load $\left(\mathrm{N} / \mathrm{m}^{2}\right)$ & \\
Joist + compression layer dead load & 3,500 \\
Flooring + ceiling dead load & 1,000 \\
Partition walls dead load & 1,000 \\
Total dead load & 5,500 \\
Quasipermanent live load & 600 \\
Service load & 6,100 \\
Total live load & 2,000 \\
Total standard load & 7,500 \\
\hline ACI 318 load test & \\
Load & 9,435 \\
Deflection increase limitation $(\mathrm{mm})$ & 3.11 \\
\hline
\end{tabular}

whether a structure may continue in use and then the evaluation of the proposed Load Factor (LF).

According to ACI 318, the analyzed area must be loaded to $0.85(1.4 D+1.7 L)$, including dead load already present. $D$ is the sum of the dead loads, and $L$ is the total live load. Therefore, the total load value for the load test is equal to $9,435 \mathrm{~N} / \mathrm{m}^{2}$ (see Table 1). If the deflection increase caused by the test satisfies $\Delta_{1} \leq l_{t}^{2} / 20,000 h$, the specimen can continue in use, where $l_{t}$ is the span between supports $(4.32 \mathrm{~m}$ in the present research) and $h$ is the specimen thickness $(0.3 \mathrm{~m})$. Thus, a deflection increase equal to $3.11 \mathrm{~mm}$ is allowed. When exceeding this limitation, retrieved deflection must be measured after the unloading. If the retrieved deformation is greater than $75 \%$, the specimen is also accepted to continue in use.

And when it has been found that the slab can remain in use, the Load Factor is analyzed in order to quantify the remaining safety and the magnitude of the necessary intervention. This factor is obtained making the ratio between the load at which each specimen reaches the permissible active deflection for the partition walls and the total standard load (total dead load + total live load). The LF relates the load that each model bears and the total load that they must bear, according to standards. According to the Spanish code on structural concrete [28], the limitation on the permissible active deflection for the partition walls of $L / 400$ is given, $L$ being the span. In this research, this value is $1.08 \mathrm{~cm}$. This deflection occurs from the moment that the partition walls are constructed. A vertical displacement of $1.08 \mathrm{~cm}$ is allowed from this moment, and the supported load in each specimen is related to the total standard load.

2.2. Specimens Geometry. Nonlinear simulations of prestressed T-joists throughout their load range were performed using the finite element method (FEM). The T-joist models are very accurate, with the real 3D geometry and the reinforcement in its exact position (Figure 3). The simulated joist is part of a one-way slab of $30 \mathrm{~cm}$ thickness with a span of $4.92 \mathrm{~m}$ between column axes, with flat beams of $60 \mathrm{~cm}$ width. Therefore the joist length is $4.32 \mathrm{~m}$.

The compression layer is centered on the joist and has $69 \mathrm{~cm}$ width, because it is the spacing between joists in the one-way slab, and $5 \mathrm{~cm}$ thickness. The reinforcement mesh inside the compression layer is composed of a $6 \mathrm{~mm}$ rod every $24 \mathrm{~cm}$ in both directions. The filler blocks are not simulated because they are not resistant elements. The prestressed joist is the T12.3 model of the Spanish company Prevalesa S. L., with four $5 \mathrm{~mm}$ prestressed tendons on three levels. The middle and the upper level have one tendon, simulated as two half tendons in order to keep the section symmetry in the simulations.

This research work comprises $12 \mathrm{~T}$-joist specimens, in which the influence of the boundary conditions, the damage level, and the CFRP strengthening are assessed. Simply supported models are from (A1) to (A6) specimens, and fixed-ended joists models are presented in (B1) to (B6) specimens. As previously stated, when a T-joist is part of a complete building, it does not behave in any of these two ways, because it is in an intermediate position between full restrain and freedom. In order to assess the increased safety in damaged joists with CFRP repair, there are six variants: healthy, extreme corrosion without CFRP repair, with 1, 2, 3, and 4 CFRP sheets.

2.3. Process of Loads and Constructive Elements. The strict simulation of the process of loads and order of appearance of structural and building elements is very important, in order 
TABLE 2: Mechanical properties of materials.

\begin{tabular}{|c|c|c|c|c|c|}
\hline & \multicolumn{5}{|c|}{ Material } \\
\hline & \multicolumn{2}{|c|}{ Concrete } & \multicolumn{2}{|c|}{ Steel } & \multirow{2}{*}{ CFRP } \\
\hline & HA-30 & HP-40 & B-500-SD & Y-1860-C & \\
\hline Density $\left(\mathrm{kN} / \mathrm{m}^{3}\right)$ & 25 & 25 & 78.5 & 78.5 & - \\
\hline Elastic modulus (GPa) & 28.6 & 30.9 & 200 & 200 & 230 \\
\hline Compression strength ( $\mathrm{MPa})$ & 38 & 48 & - & - & - \\
\hline Tensile strength (MPa) & 3.39 & 3.96 & - & - & 4850 \\
\hline Poisson's ratio & 0.2 & 0.2 & 0.3 & 0.3 & - \\
\hline Yielding strength $(\mathrm{MPa})$ & - & - & 500 & 1581 & - \\
\hline Ultimate strain & - & - & - & - & 0.02 \\
\hline Element type & SOLID65 & SOLID65 & LINK180 & Prest. F & SHELL181 \\
\hline
\end{tabular}

to capture the behavior and get the closest results to the actual situation when the joist is part of a complete building.

The simulated steps, which correspond with real steps in the constructive process and are summarized in Table 1, are the following:

(i) Prestressed joist: in a first step, only the prestressed joist is simulated, and therefore at this point only these elements are active. The prestress is introduced as equivalent prestressing forces at the corresponding points. The equivalent force per $5 \mathrm{~mm}$ diameter rebar is equal to $17,000 \mathrm{~N}$, after a $29 \%$ loss over infinite time. At the end of this step, the joist has a negative deflection, as in reality.

(ii) Structural dead load: in a second step, the concrete is poured in situ in order to complete the slab thickness and the compression layer.

(iii) Flooring and ceiling dead load: these constructive elements appear in this moment and are simulated as a load increment of $1,000 \mathrm{~N} / \mathrm{m}^{2}$.

(iv) Partition walls dead load: now, the partition walls appear as a dead load increment of $1,000 \mathrm{~N} / \mathrm{m}^{2}$. The active deflection with respect to the partition walls will start as soon as this load is completely added. This deflection is limited to $1.08 \mathrm{~cm}$ in the assessed specimens, due to their length.

(v) Service load: when the building is finished, the T-joist is supporting the service load. The service load is the load to which the structure will be subjected most of its useful life. It consists of the dead loads and the quasipermanent part of the live load, according to the standard CTE-06 [29]. The characteristic value of the live load for housing in Spain is $2,000 \mathrm{~N} / \mathrm{m}^{2}$, and the quasipermanent value is $600 \mathrm{~N} / \mathrm{m}^{2}$.

(vi) Corrosion: corrosion damage appears during the service life. The most severe pathological cases are assessed in this research. Therefore, the corrosion is modeled as the removal of the lower level of prestressed tendons and the concrete cover spalling, as it may occur in some extreme cases. But the other two levels of prestressed tendons are maintained, because they continue to assist in supporting the joist. The assessment of the most severe cases provides the lowest value of failure load, so that it is on the side of safety. Due to their boundary conditions, simply supported specimens experience a large vertical displacement at midspan if the disappearance of the lower tendons and concrete cover is simulated to the load corresponding to the service load $\left(6,100 \mathrm{~N} / \mathrm{m}^{2}\right)$. Because of this, corrosion was simulated to a lower load value in these cases $\left(4,000 \mathrm{~N} / \mathrm{m}^{2}\right)$, and from this point, the following load steps were loaded successively as explained in this part. This consideration does not affect the results of the research, since the objective is to assess residual safety and achieve adequate safety at the end.

(vii) CFRP sheet: the prefabricated sheets are bonded to the tension side of the specimens after sandblasting, brushing, and cleaning the concrete surface to guarantee a good bond between the adhesive and the concrete [30]. The choice and placement of the CFRP sheet must follow the ACI Committee 440 guidelines [31].

(viii) Total standard load: at this point, the specimens are loaded with the total live load, in order to reach the total standard load. This is the total load that the slab must support according to standards.

(ix) Load until failure: finally, the T-joist is loaded until collapse.

2.4. Materials. For the T-joist specimens, the simulation of the behavior of five materials is needed: two types of concrete and two types of steel and the CFRP sheet. Because the joists are prefabricated and the rest of the reinforced concrete $\mathrm{T}$ joist is constructed in situ, different qualities of both steel and concrete appear. The assessed prestressed joist is the T12.3 model of the Spanish company Prevalesa S. L., with four $5 \mathrm{~mm}$ prestressed tendons on three levels. HP-40 concrete and Y-1860-C high performance prestressing steel form precast joists. Instead, the concrete in situ is the commonly used HA-30 and the steel reinforcements are made with B-500-SD steel. In addition, CFRP sheets are placed to repair damaged specimens. The chosen CFRP sheet for this research work is MAPEI MapeWrap C UNI-AX 300/10 with $0.166 \mathrm{~mm}$ thickness. Table 2 summarizes the mechanical properties of the employed materials. 
2.5. Finite Element Model. The finite element method (FEM) is conducted to simulate the behavior of the test specimens in ANSYS software. The investigated T-joist specimens were developed in three-dimensional models in order to account for the materials nonlinear behavior.

Eight-node solid brick elements (Solid65) were used to simulate the concrete. This solid is capable of cracking in tension and crushing in compression, creep nonlinearity, and large deflection geometrical nonlinearity. The concrete requires multilinear isotropic material properties and the Willam-Warnke [32] spatial failure criteria to properly model its behavior. The uniaxial stress-strain relation was defined by the civil engineering Eurocode. Two simulation techniques have been used for steel reinforcements. The prestressed bars of the precast joist are introduced as equivalent prestressing forces at the corresponding points, and 3D spar elements (Link180) were employed to simulate the reinforcement mesh inside the compression layer. This three-dimensional element is a uniaxial tension-compression element with three degrees of freedom at each node. Plasticity, creep, swelling, stress stiffening, and large deflection capabilities are included. The steel is assumed to be an elastic-perfectly plastic material and identical in tension and compression, and its behavior can be simplified by an isotropic bilinear curve. And finally, a shell element (Shell181) was used to simulate the CFRP sheets. It is a four-node $3 \mathrm{D}$ element with six degrees of freedom at each node and is well-suited for linear, large rotation, and/or large strain nonlinear applications. The CFRP-material is considered as linear elastic until failure. This type of element needs a failure criterion for the complete definition of behavior. The physical failure criteria are specially formulated to account for different damage mechanisms (fiber and matrix failure) in fiber-reinforced composite materials. Hashin maximum stress failure criteria were used in this research [33] for the CFRP sheets. To complete the material damage definition, it is also necessary to specify a compatible damage initiation criteria and evolution law. Progressive damage evolution based on continuum damage mechanism was chosen. In this case, energies dissipated per unit area $G_{C}$ are specified individually for all damage modes (fiber tension, fiber compression, matrix tension, and matrix compression). For a specific damage mode, $G_{C}$ is given by

$$
G_{C}=\int_{0}^{U_{e}^{f}} \sigma_{e} d U_{e} .
$$

where $\sigma_{e}$ is the equivalent stress, $U_{e}$ is the equivalent displacement, and $U_{e}^{f}$ is the ultimate equivalent displacement, where total material stiffness is lost for the specific mode [34]. For complex stress state, the equivalent stresses and strains are calculated based on Hashin failure criteria. Viscous damping coefficients $\eta$ are also specified respectively for all four damage modes. For a specific damage mode, the damage evolution is regularized as follows:

$$
d_{t+\Delta t}^{\prime}=\frac{\eta}{\eta+\Delta t} d_{t}^{\prime}+\frac{\Delta t}{\eta+\Delta t} d_{t+\Delta t}
$$

where $d_{t+\Delta t}^{\prime}$ is the regularized damage variable at current time, $d_{t}^{\prime}$ is the regularized damage variable at the end of the
TABLE 3: Esfahani et al. test results of reinforcing bars.

\begin{tabular}{lccc}
\hline Bar diameter (mm) & 8 & 10 & 16 \\
Yielding stress (MPa) & 350 & 365 & 406 \\
Ultimate stress (MPa) & 459 & 572 & 583 \\
\hline
\end{tabular}

last substep, and $d_{t+\Delta t}$ is the unregularized current damage variable [34].

Half of the T-joist specimen has been simulated, seeking to optimize computing time. Therefore, it was necessary to simulate suitable boundary conditions to behave in the same manner as the complete T-joist. The simulated boundary conditions were of symmetry at the midspan, allowing the vertical displacement and roller support or embedding in the end, according to the assessed model. A total of 5679 elements were required for T-joist analysis (5040 3D elements, 423 link elements, and 216 shell elements). The total nodes of each specimen were 7592. Most of the concrete elements are a prism with $30 \times 30 \times 30 \mathrm{~mm}$. The choice of mesh size was based on preliminary studies in which different sizes were used [35]. This number of elements represents a good balance between the computational time and the numerical accuracy of results.

The Newton-Raphson equilibrium iterations were used in the nonlinear solutions. Convergence criteria for the specimens were based on force and displacement. The convergence tolerance limits were selected by analysis program [36].

In this study, a perfect bond between concrete and steel was assumed. The nodes of the CFRP elements are also connected to those of adjacent concrete elements [37]. The interaction between the concrete joist and the CFRP is modeled without considering debonding. The bond does not have to be explicitly modeled in the numerical analysis [38].

The ANSYS software allows the generation of load steps and the birth and death of elements in the different steps. The cases of corrosion evaluated in this work are the most severe, involving the total loss of the concrete cover and the lower level of tendons. Therefore, corrosion is simulated in the model by the death of the elements constituting the cover and the lower reinforcement in the proper load step.

2.6. Model Verification. A very careful calibration of the numeric simulations has been made in order to verify the accuracy of the used hypothesis and models regarding the behavior of CFRP sheets. The FE software is used to predict the flexural behavior of strengthened beams reported by Esfahani et al. [39] in order to validate the research methodology and its results and final conclusions.

For the Esfahani et al. specimens, the design compressive strength of $25 \mathrm{MPa}$ was used for concrete and different sizes of reinforcing bars were used in specimens. The yield and ultimate strength of different bars are given in Table 3. The mechanical properties of CFRP are the following: the ultimate strain is 0.012 , the tensile strength is $2845 \mathrm{MPa}$, and the modulus of elasticity is $237 \mathrm{GPa}$. Reaction force versus CFRP strain relationship in simulated sheet can be seen in Figure 4.

The specimens (B5) and (B7) were selected. The dimensions details of the beam are shown in Figure 5. The $8 \mathrm{~mm}$ 
TABLE 4: Load at permissible active deflection, Load Factor values, and ACI 318 load test results for simulated specimens.

\begin{tabular}{|c|c|c|c|c|c|}
\hline Specimen & & & $\begin{array}{c}\text { Load at } \\
\text { permissible } \\
\text { active deflection } \\
\left(\mathrm{N} / \mathrm{m}^{2}\right)\end{array}$ & $\begin{array}{l}\text { Load } \\
\text { Factor } \\
\text { (LF) }\end{array}$ & $\begin{array}{l}\text { ACI } 318 \\
\text { load test }\end{array}$ \\
\hline \multirow{6}{*}{ Simply supported joist } & (A1) & Healthy & 9,984 & 1.33 & Right \\
\hline & (A2) & Corroded without repair & 5,216 & 0.70 & Negative \\
\hline & (A3) & Corroded with 1 CRRP sheet & 5,960 & 0.79 & Negative \\
\hline & $(\mathrm{A} 4)$ & Corroded with 2 CRRP sheets & 7,085 & 0.94 & Negative \\
\hline & (A5) & Corroded with 3 CRRP sheets & 8,107 & 1.08 & Negative \\
\hline & $(\mathrm{A} 6)$ & Corroded with 4 CRRP sheets & 9,080 & 1.21 & Negative \\
\hline \multirow{6}{*}{ Fixed-ended joist } & (B1) & Healthy & 18,685 & 2.49 & Right \\
\hline & (B2) & Corroded without repair & 14,520 & 1.93 & Right \\
\hline & (B3) & Corroded with 1 CRRP sheet & 15,706 & 2.09 & Right \\
\hline & (B4) & Corroded with 2 CRRP sheets & 16,874 & 2.26 & Right \\
\hline & (B5) & Corroded with 3 CRRP sheets & 17,589 & 2.33 & Right \\
\hline & (B6) & Corroded with 4 CRRP sheets & 18,096 & 2.42 & Right \\
\hline
\end{tabular}

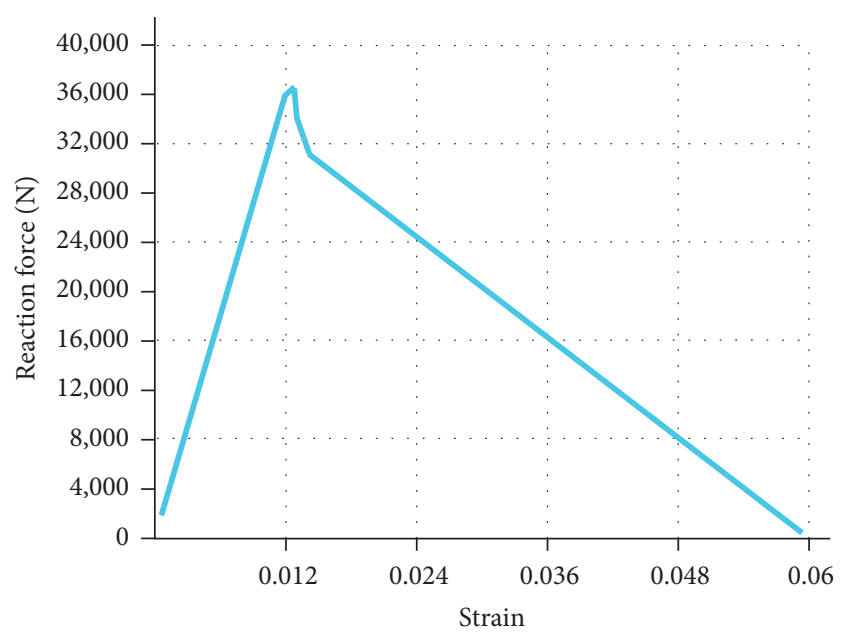

FIGURE 4: Reaction force versus strain relationship in simulated CFRP sheet.

steel rods are employed for stirrups each $80 \mathrm{~mm}$. The nominal thickness and width of the CFRP were $0.176 \mathrm{~mm}$ and $150 \mathrm{~mm}$, and the specimen (B7) was strengthened with one CFRP sheet.

All specimens have been reproduced successfully in FE software. A good correspondence in the behavior of the different models has been achieved, following their specifications when performing the simulations. A great concordance in the load-displacement curves has been obtained in all cases. In Figure 6 the B5 and B7 specimens are shown, as an illustrative example, where it can be seen that our work improves the correlation between the results of the analytical and the experimental study. The validated results are consistent in all models, so that both the software and the materials properties are accepted as valid tools for the research.

\section{Results and Discussion}

The prestressed T-joists simulation throughout their load range has been performed. Load-vertical displacement plots at midspan are compared in healthy, corroded, and repaired models in order to assess the residual safety. Figures 7 and 8 represent the load-vertical displacement at midspan relationships for the 12 specimens. Table 4 shows the load at permissible active deflection, the Load Factor (LF) values, and ACI 318 load test results for simulated specimens.

Several aspects can be seen in a deep analysis of the loadvertical displacement curves, which are as follows:

(i) The initial precamber produced by the process of prestressing in prefabrication.

(ii) The horizontal stretch due to corrosion: the end of this step is the starting point for the simulation of the load test acceptance criterion of existing structures proposed by the ACI 318. For simply supported specimens, it must be remembered that cases with severe corrosion have a large vertical displacement if corrosion appears at $6100 \mathrm{~N} / \mathrm{m}^{2}$, so that the corrosion has been simulated to a load of $4000 \mathrm{~N} / \mathrm{m}^{2}$. But load test is correctly performed from the service load, with the deflection that the T-joist would have in service life with pathology. The Load Factor has also been obtained with the permissible active deflection from the appearance of the partition walls.

(iii) ACI 318 load test evaluation: this test determines whether a structure can remain in use, and its compliance is graphically analyzed in Figures 7 and 8. The procedure consists of limiting graphically the service load and ACI 318 load test and then also limiting the allowed deflection increase.

(iv) Load Factor: the load supported at permissible active deflection for the partition walls and the standard 


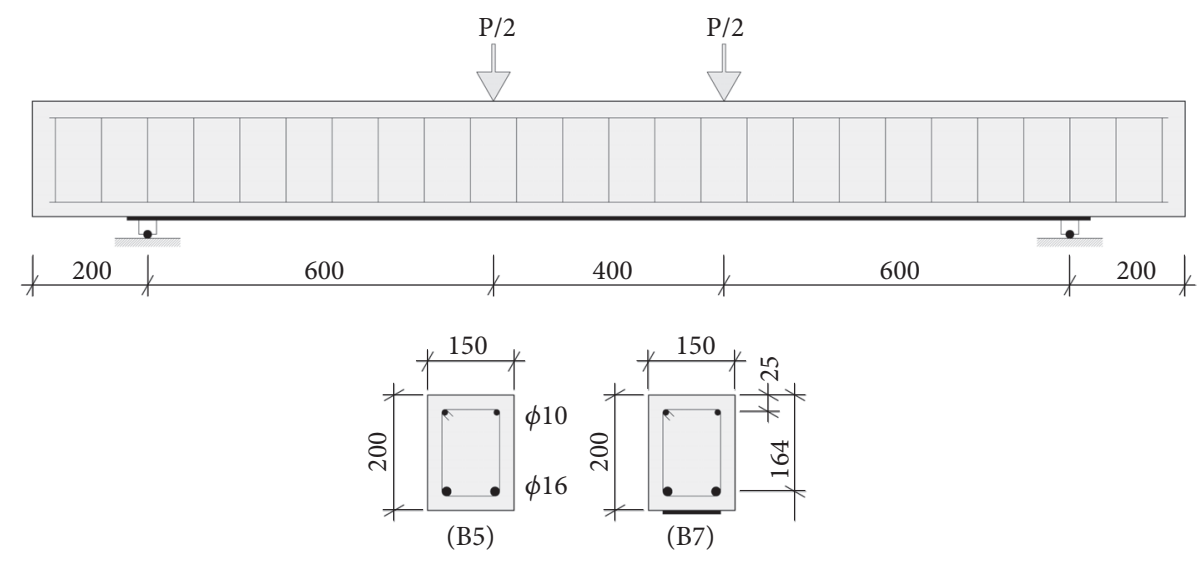

FIGURE 5: Details of Esfahani et al. beam specimens.

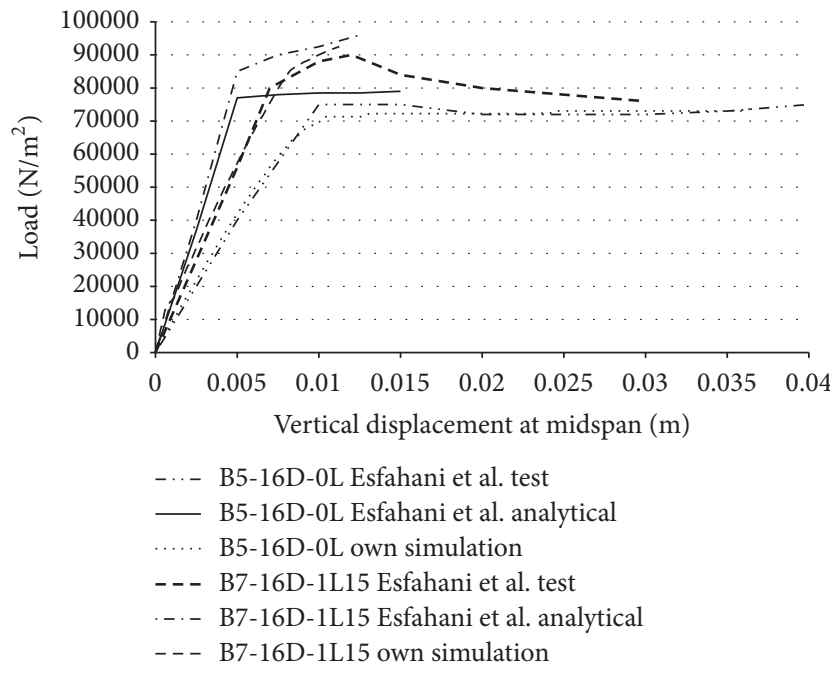

FIGURE 6: Load versus vertical displacement relationship for B5 and B7 Esfahani et al. specimens. Comparison of Esfahani et al. test results and analytical predictions with our simulations.

load can be analyzed in Figures 7 and 8 and graphically understand the relationship with which the Load Factor is obtained.

Simply supported damaged specimens do not withstand the loads established by Building Technical Code CTE-06 [40] with less than 3 CFRP sheets ((A2), (A3), and (A4) specimens), so they have a Load Factor of less than 1. A safety coefficient of 1.08 and 1.21 was obtained with 3 and 4 sheets, respectively ((A5) and (A6) specimens), remaining with an unacceptable safety in structure analysis. In addition, no simply supported damaged specimen meets the criteria for continue in use of the ACI 318, even with 4 CFRP sheets. Severe corrosion in the simply supported specimen causes a $47.4 \%$ reduction in the ultimate capacity of the T-joist. The inclusion of CFRP sheets improves the bearing capacity of the specimen with respect to the damaged joist without repair as follows:

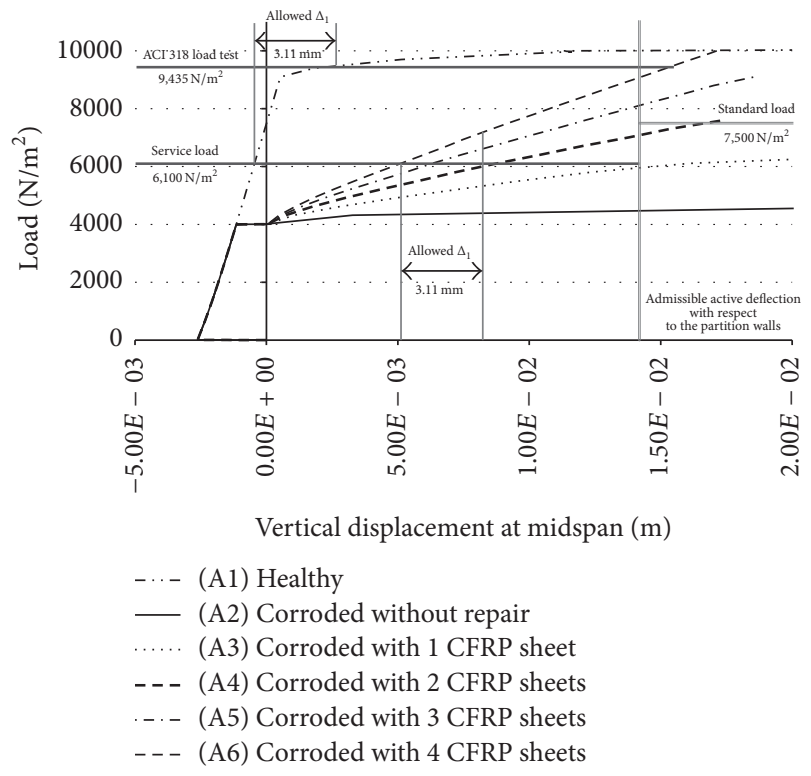

FIGURE 7: Load-vertical displacement at midspan curves for simply supported T-joist specimens.

$+12.9 \%$ with 1 sheet, $+34.3 \%$ with 2 sheets, $+54.3 \%$ with 3 sheets, and $+72.9 \%$ with 4 sheets, not reaching initial safety.

Fixed-ended damaged T-joist without repair ((B2) specimen) support the loads established by the standard with a safety coefficient of 1.93, almost double of the standard load (dead loads + live loads). When gluing one CFRP sheet, the Load Factor 2 is exceeded, and with 2, 3, and 4 sheets, the safety coefficients of $2.26,2.33$, and 2.42 , respectively, are reached. All studied fixed-ended specimens can continue in use according to ACI 318 . The complete corrosion of the lower level of tendons and the loss of the concrete cover in the fixedended specimen causes a $22.5 \%$ reduction in the ultimate capacity. The capacity of the severe damaged T-joist is improved with the inclusion of CFRP sheets as follows: $+8.3 \%$ with 1 sheet, $+17.1 \%$ with 2 sheets, $+20.7 \%$ with 3 sheets, and $+25.4 \%$ with 4 sheets, getting close to recovering initial safety. 


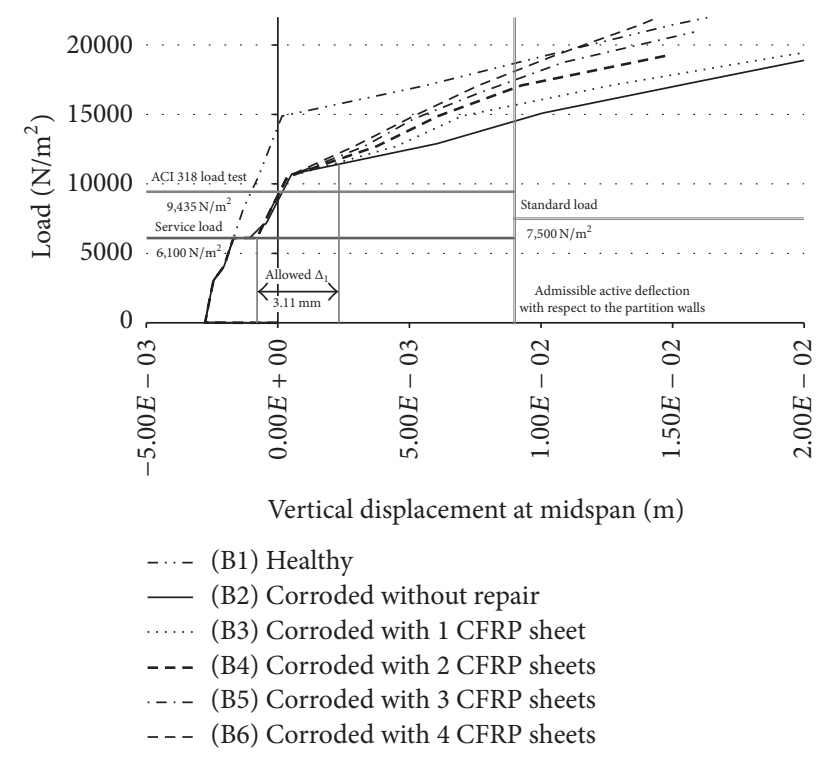

Figure 8: Load-vertical displacement at midspan curves for fixedended T-joist specimens.

Severe corrosion reduces the ultimate capacity of the simply supported T-joists in a more noticeable way. But, on the other hand, the addition of CFRP sheets improves to a greater extent the capacity of this type of joists.

The regulations establish clear safety coefficients for the calculation of structures in new construction, where they have a great control of the materials and the processes of construction. The acceptable Load Factor in cases of rehabilitation remains the responsibility of the expert performing the project and depends on local standards. Anyway, it seems sensible to assume a value near 2 as a minimum, depending on the reliability of the materials tests.

\section{Conclusions}

The actual boundary conditions of a T-joist when it is part of an entire one-way slab are in an intermediate case of restriction on the ends, neither totally free nor totally restrained. The evaluation of the two extreme theoretical cases presented in this paper is very important because it allows the technician to establish some actuation limits.

Cases of severely damaged simply supported T-joist do not support the service load without the help of neighboring joists. The added stiffness by strengthening with CFRP sheets with low thickness does not solve the problem, and it can not be accepted as constructive solution. Vertical displacement can not be controlled according to EHE-08 [28], even in the case with the addition of 4 CFRP sheets. Damaged simply supported specimens do not meet the ACI 318 load test to maintain the structure in use, not even with 4 CFRP sheets. Perhaps proper safety can be reached with a higher number of sheets, but it is not a common solution. The most common cases in actual practice are in which one or two sheets are used. Load Factor assessment indicates that none of the repairs reaches an acceptable safety, notwithstanding the loads with the safety factors established by the standards. Our experience tells us that if there is a group of contiguous and hardly damaged joists in a one-way slab, the loads transmission perpendicular to joists force them to collaborate one with each other. Despite the damage in the lower tendons, damage may not appear in the rest of construction elements in some cases. But even if the damage does not appear on the other elements, an immediate shoring up and deep repair are necessary.

The boundary conditions in the cases of fixed-ended Tjoists are theoretical. This degree of embedment is attainable in the central bays of slabs with a large symmetry of spans or with a very small difference in lengths. It is remarkable that in the evaluated real cases of this type of slab it can be seen that in spite of a great deterioration in the joists no cracking or damage appears in the other elements of the building. This can be understood watching the simulations of these cases with severe corrosion, where the vertical displacement at midspan with heavy loads remains small in magnitude. The ACI 318 load test for these cases of isolated T-joist with a span of $4.32 \mathrm{~m}$ indicates the meeting of all safety criteria. The simulation of the load test in these specimens gives vertical displacements around $30 \%$ of standard limitation, because the boundary conditions maintain a high stiffness, even with a severe degree of corrosion. The Load Factor for all these cases exceeds the safety factors proposed by standards. It is noted that the case with four CFRP sheets recovers the initial safety.

\section{Conflicts of Interest}

The authors declare that there are no conflicts of interest regarding the publication of this paper.

\section{References}

[1] Instituto de Tecnología de la Construcción (ITeC), Informe Euroconstruct, Instituto de Tecnología de la Construcción, Barcelona, Spain, 2015.

[2] J. A. Vieitez Chamosa and J. L. Ramírez Ortiz, "Patología de la construcción en España: aproximación estadística," Informes de la Construcción, vol. 36, no. 364, pp. 5-15, 1984.

[3] Instituto Valenciano de la Edificación (IVE), Guía para la Inspección y Evaluación Preliminar de Estructuras de Hormigón en Edificios Existentes, Serie Guías de la Calidad, Generalitat Valenciana-Conselleria de Medi Ambient, Aigua, Urbanisme i Habitatge, Valencia, Spain, 2008.

[4] Instituto Valenciano de la Edificación (IVE), Experiencia en Inspección de Estructuras en Edificios. Comunidad Valenciana 1991-2008, Serie Guías de la Calidad, Generalitat ValencianaConselleria de Medi Ambient, Aigua, Urbanisme i Habitatge, Valencia, Spain, 2008.

[5] L. Anania, A. Badalà, and G. Failla, "Increasing the flexural performance of RC beams strengthened with CFRP materials," Construction and Building Materials, vol. 19, no. 1, pp. 55-61, 2005.

[6] F. A. Fathelbab, M. S. Ramadan, and A. Al-Tantawy, "Strengthening of RC bridge slabs using CFRP sheets," Alexandria Engineering Journal, vol. 53, no. 4, pp. 843-854, 2014. 
[7] A. Khalifa and A. Nanni, "Improving shear capacity of existing RC T-section beams using CFRP composites," Cement and Concrete Composites, vol. 22, no. 3, pp. 165-174, 2000.

[8] H. M. Tanarslan, "The effects of NSM CFRP reinforcements for improving the shear capacity of RC beams," Construction and Building Materials, vol. 25, no. 5, pp. 2663-2673, 2011.

[9] J. Dong, Q. Wang, and Z. Guan, "Structural behaviour of RC beams with external flexural and flexural-shear strengthening by FRP sheets," Composites Part B: Engineering, vol. 44, no. 1, pp. 604-612, 2013.

[10] H. Toutanji, M. Han, J. Gilbert, and S. Matthys, "Behavior of large-scale rectangular columns confined with FRP composites," Journal of Composites for Construction, vol. 14, no. 1, pp. 62-71, 2010.

[11] B. Csuka and L. P. Kollár, "Analysis of FRP confined columns under eccentric loading," Composite Structures, vol. 94, no. 3, pp. 1106-1116, 2012.

[12] C. Desprez, J. Mazars, P. Kotronis, and P. Paultre, "Damage model for FRP-confined concrete columns under cyclic loading," Engineering Structures, vol. 48, pp. 519-531, 2013.

[13] A. M. Ceci, J. R. Casas, and M. Ghosn, "Statistical analysis of existing models for flexural strengthening of concrete bridge beams using FRP sheets," Construction and Building Materials, vol. 27, no. 1, pp. 490-520, 2012.

[14] F. Inam, D. W. Y. Wong, M. Kuwata, and T. Peijs, "Multiscale hybrid micro-nanocomposites based on carbon nanotubes and carbon fibers," Journal of Nanomaterials, vol. 2010, Article ID 453420, 12 pages, 2010.

[15] M.-Y. Shen, T.-Y. Chang, T.-H. Hsieh et al., "Mechanical properties and tensile fatigue of graphene nanoplatelets reinforced polymer nanocomposites," Journal of Nanomaterials, vol. 2013, Article ID 565401, 9 pages, 2013.

[16] H. T. Choi, J. S. West, and K. A. Soudki, "Partially bonded near-surface-mounted CFRP bars for strengthened concrete Tbeams," Construction and Building Materials, vol. 25, no. 5, pp. 2441-2449, 2011.

[17] N. Attari, S. Amziane, and M. Chemrouk, "Flexural strengthening of concrete beams using CFRP, GFRP and hybrid FRP sheets," Construction and Building Materials, vol. 37, pp. 746757, 2012.

[18] Y. Shen, S. Lu, and F. Li, "An experimental study on concrete flat slabs prestressed with carbon fibre reinforced polymer sheets," Advances in Materials Science and Engineering, vol. 2015, Article ID 792320, 11 pages, 2015.

[19] M. M. Önal, "Strengthening reinforced concrete beams with CFRP and GFRP," Advances in Materials Science and Engineering, vol. 2014, Article ID 967964, 8 pages, 2014.

[20] J. F. Bonacci and M. Maalej, "Behavioral trends of RC beams strengthened with externally bonded FRP," Journal of Composites for Construction, vol. 5, no. 2, pp. 102-103, 2001.

[21] S. T. Smith and J. G. Teng, "FRP-strengthened RC beams. I: review of debonding strength models," Engineering Structures, vol. 24, no. 4, pp. 385-395, 2002.

[22] A. F. Ashour, S. A. El-Refaie, and S. W. Garrity, "Flexural strengthening of RC continuous beams using CFRP laminates," Cement and Concrete Composites, vol. 26, no. 7, pp. 765-775, 2004.

[23] H. K. Lee and L. R. Hausmann, "Structural repair and strengthening of damaged RC beams with sprayed FRP," Composite Structures, vol. 63, no. 2, pp. 201-209, 2004.
[24] A. H. Al-Saidy and K. S. Al-Jabri, "Effect of damaged concrete cover on the behavior of corroded concrete beams repaired with CFRP sheets," Composite Structures, vol. 93, no. 7, pp. 1775-1786, 2011.

[25] S. Pirayeh Gar, J. B. Mander, M. Head, and S. Hurlebaus, "FRP slab capacity using yield line theory," Journal of Composites for Construction, vol. 18, no. 6, 2014.

[26] J. Vercher, E. Gil, A. Mas, and C. Lerma, "Diagnosis and intervention criteria in slabs damaged by severe corrosion of prestressed joists," Journal of Performance of Constructed Facilities, vol. 29, no. 1, 2015.

[27] ACI Committee 318, ACI 318-08: Building Code Requirements for Structural Concrete and Commentary. Strength Evaluation of Existing Structures, American Concrete Institute, Detroit, Mich, USA, 2008.

[28] Ministerio de Fomento, EHE-08: Instrucción de Hormigón Estructural, Boletín Oficial del Estado, Madrid, Spain, 2008.

[29] Ministerio de Vivienda, CTE-06: Código Técnico de la Edificación, Boletín Oficial del Estado, Madrid, Spain, 2006.

[30] G. Camata, E. Spacone, and R. Zarnic, "Experimental and nonlinear finite element studies of RC beams strengthened with FRP plates," Composites Part B: Engineering, vol. 38, no. 2, pp. 277-288, 2007.

[31] ACI Committee 440, ACI 440.2R-08: Guide for the Design and Construction of Externally Bonded FRP Systems for Strengthening Concrete Structures, American Concrete Institute, Detroit, Mich, USA, 2008.

[32] K. J. Willam and E. D. Warnke, "Constitutive model for the triaxial behavior of concrete," in Proceedings of the International Association for Bridge and Structural Engineering (ISMES '75), vol. 19, p. 30, Bergamo, Italy, 1975.

[33] Z. Haszin, "Failure criteria for unidirectional fiber composites," Journal of Applied Mechanics, Transactions ASME, vol. 47, no. 2, pp. 329-334, 1980.

[34] ANSYS Academic Research, Release 15.0, ANSYS Help, ANSYS, Inc.

[35] J. Vercher, E. Gil, and A. Mas, Load-Bearing Capacity of Corroded Reinforced Concrete Joists, Structures and Architecture: Concepts, Applications and Challenges, Taylor \& Francis Group, London, UK, 2013.

[36] Y. Zhou, M. Gou, F. Zhang, S. Zhang, and D. Wang, "Reinforced concrete beams strengthened with carbon fiber reinforced polymer by friction hybrid bond technique: experimental investigation," Materials and Design, vol. 50, pp. 130-139, 2013.

[37] A. Agbossou, L. Michel, M. Lagache, and P. Hamelin, "Strengthening slabs using externally-bonded strip composites: analysis of concrete covers on the strengthening," Composites Part B: Engineering, vol. 39, no. 7-8, pp. 1125-1135, 2008.

[38] O. Enochsson, J. Lundqvist, B. Täljsten, P. Rusinowski, and T. Olofsson, "CFRP strengthened openings in two-way concrete slabs-An Experimental And Numerical Study," Construction and Building Materials, vol. 21, no. 4, pp. 810-826, 2007.

[39] M. R. Esfahani, M. R. Kianoush, and A. R. Tajari, "Flexural behaviour of reinforced concrete beams strengthened by CFRP sheets," Engineering Structures, vol. 29, no. 10, pp. 2428-2444, 2007.

[40] Ministerio de Vivienda, Código Técnico de la Edificación (CTE), Boletín Oficial del Estado, Madrid, Spain, 2006. 

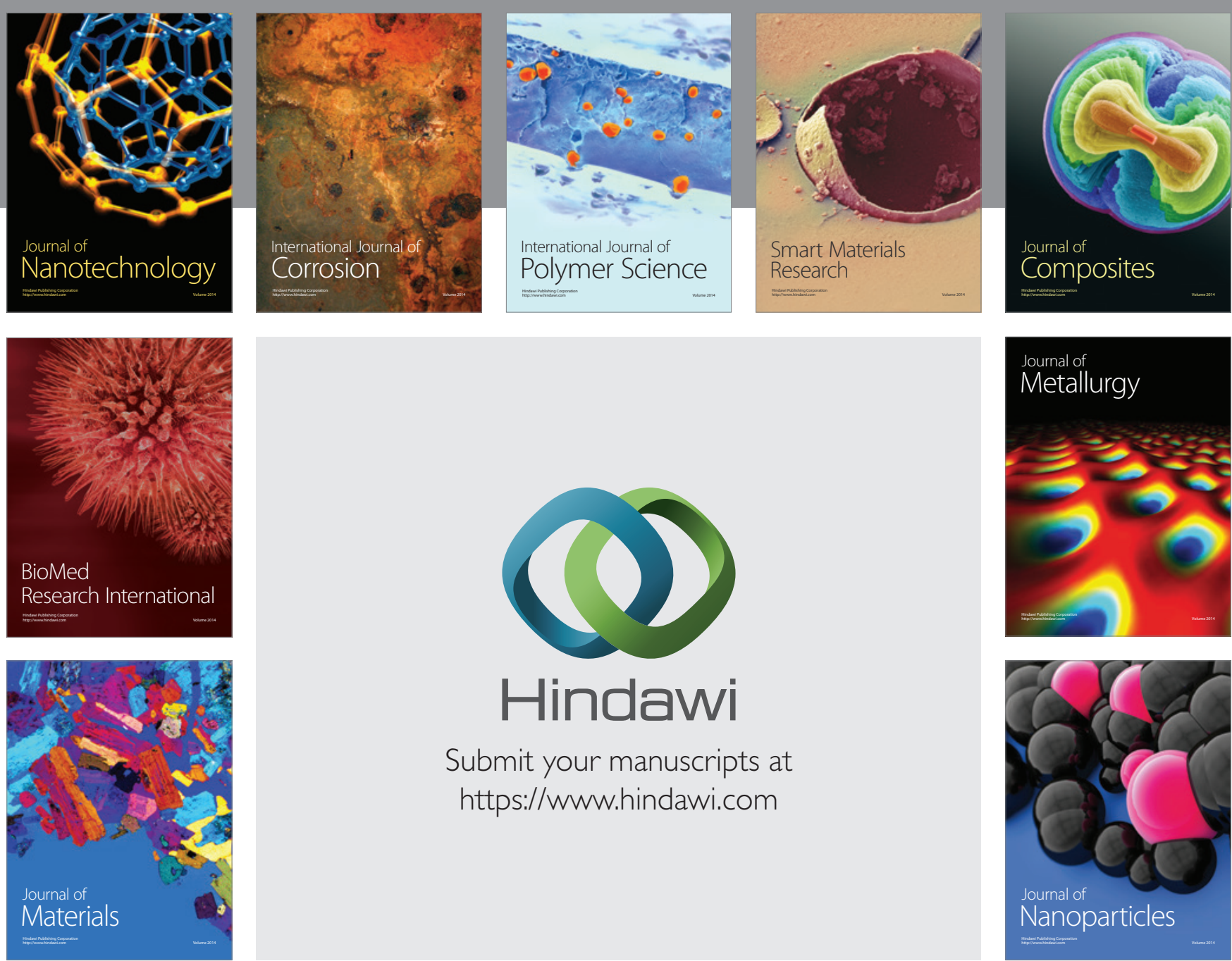

\section{Hindawi}

Submit your manuscripts at

https://www.hindawi.com

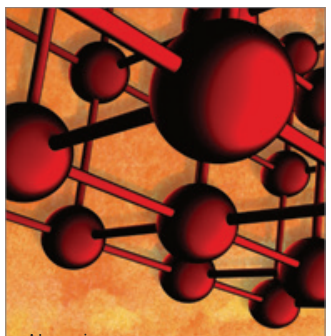

Materials Science and Engineering
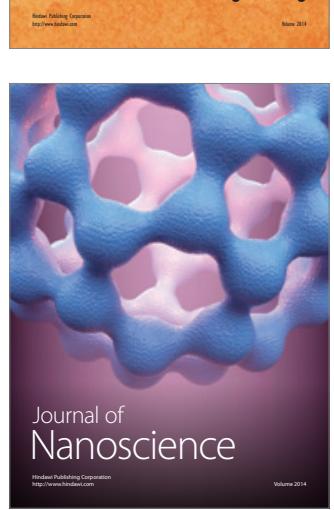
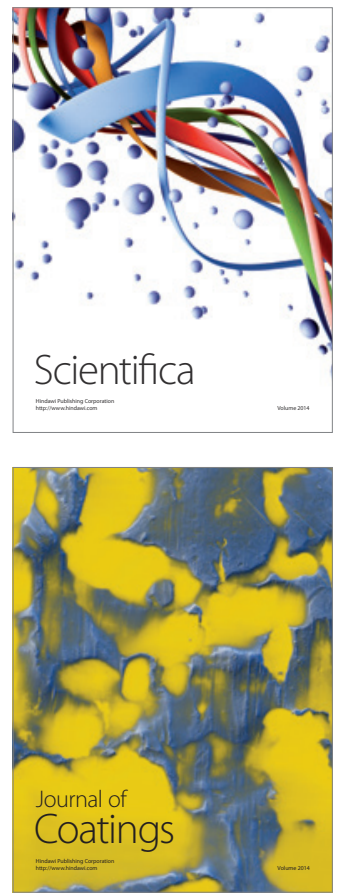
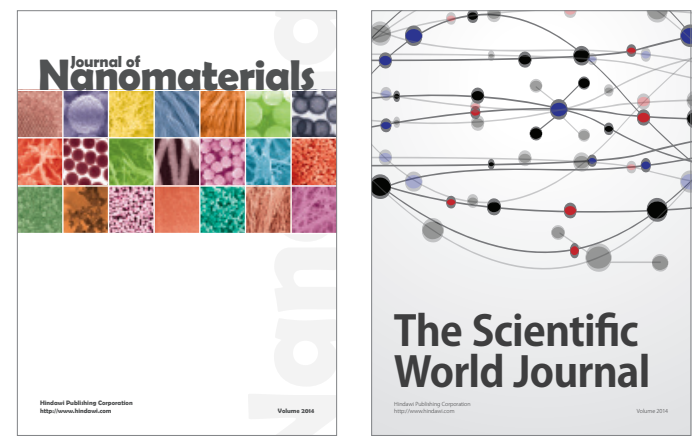

The Scientific World Journal
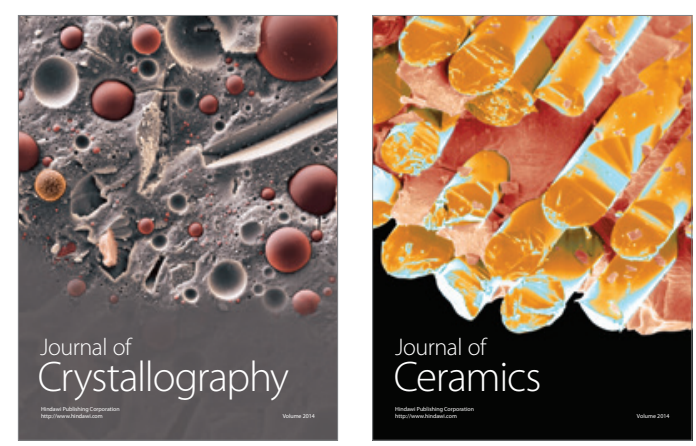
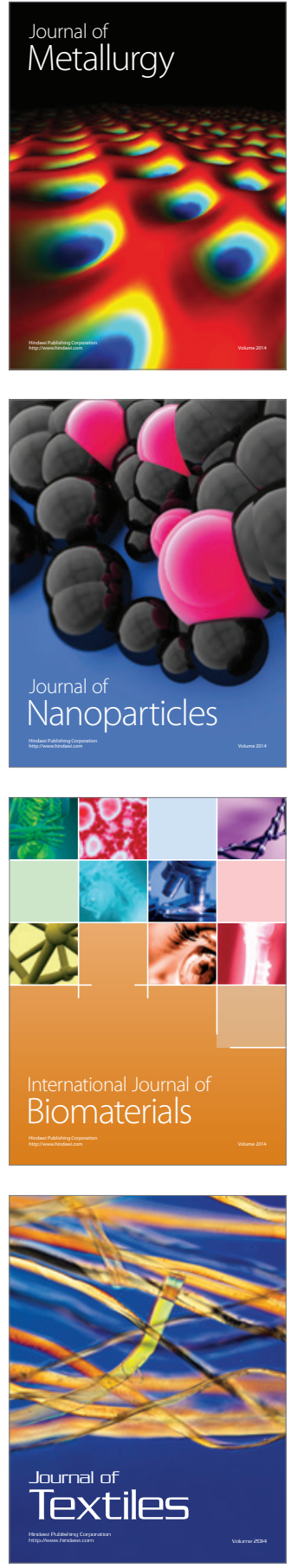